\title{
The Westward Drift of the Earth's Magnetic Field in Historic Times
}

\author{
Takesi YukuTAKE* \\ Dominion Observatory, Ottawa, Canada \\ (Received February 18, 1967)
}

\begin{abstract}
Old records of magnetic measurements and archeomagnetic data at various places were collected to examine whether the westward drift has been a persisting feature of the earth's magnetic field and to investigate the extent to which drifting of the field has contributed to the observed secular variation.

It turned out that main features of the secular variation such as maxima and minima of magnetic declination and inclination were very likely to have drifted westwards with a velocity of about $0.36^{\circ} /$ year over several hundred years.

Comparison of the observed time variation with the spatial distribution of the present geomagnetic field suggests that the westward drift of the non-dipole field is responsible for producing a large part of the secular variation, even for such long period as 1000 years.
\end{abstract}

\section{Introduction}

It has recently been revealed that the largest part of the observed secular variation in the geomagnetic field, during several tens of years, can be attributed to the effect of the westward drift of the non-dipole field (Yukutake 1962, Nagata 1962, Adam et al 1964). This paper attempts to examine how long the present distribution of the non-dipole field has persisted and the extent to which the drifting of the earth's field has contributed to producing the observed secular variation over hundreds of years.

The westward drift of the main features of the earth's field has long been known. Halley (1692) pointed out that a place of zero declination had moved about $23^{\circ}$ from Cape d'Agulhas to the meridian of St. Helena in 90 years (i.e. with a mean westward velocity of $0.26^{\circ}$ /year). He also noticed that a magnetic anomaly in the American Continent had moved westwards $46^{\circ}$ during the same period (giving a drift velocity of $0.5^{\circ}$ /year). Bauer (1895) examined the westward movement of agonic lines where magnetic declination is zero. In Figure 1, the change in longitude of the intersection of west agonic line with the equator with the lapse of time is plotted. This shows that the intersection moves westward with a velocity of $0.23 \pm 0.005^{\circ}$ year. The corresponding point for the east agonic line has also moved westwards, but much more irregularly, giving a velocity $0.14 \pm 0.016^{\circ} /$ year for the period from 1540 to 1885 , and $0.08 \pm 0.016^{\circ}$ /year for the period from 1540 to 1960 . By extrapolating back to 1600 A.D., Carlheim-Gyllensköld (1896) found expressions for magnetic potentials all over the world at different epochs, and noticed westerly drifting of the spherical

* Present Address : Earthquake Research Institute, University of Tokyo, Tokyo 
harmonics with different velocities. Burlatskaya et al (1965) examined archeomagnetic data and concluded that the secular variation in inclination had drifted westward with a mean rate of $0.23^{\circ} /$ year during the period from 1200 to 1800 . From these it may well be surmised that the westward drift has been a pesistent feature of the geomagnetic field for at least several hundred years.

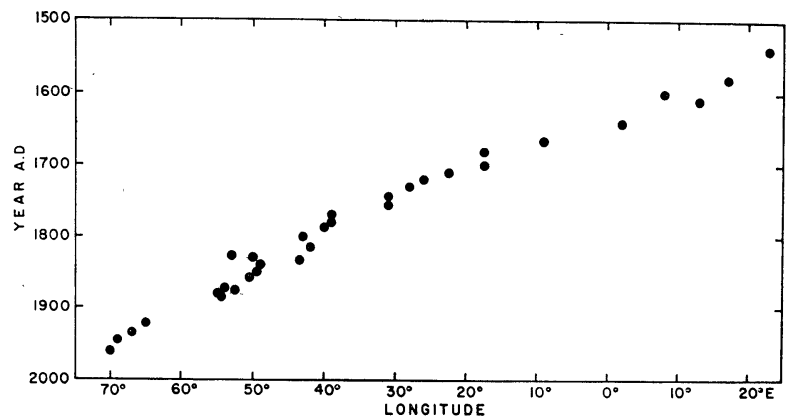

Fig. 1 Variation in the longitude of the intersection of west agonic line with the equator (Bauer 1895).

In this century, based on more accurate analysis of the geomagnetic field (e.g. see Vestine et al, 1947) the westward rotation of the magnetic field has been established quantitatively in various ways; such as movement of individual spherical harmonics (Bullard et al 1950, Nagata 1962, Yukutake 1962, Adam et al 1964, see also Hide 1966 p. 640), or the rotation of the eccentric dipole (Vestine 1953, Nagata 1962), or the drift of the non-dipole field on a planetary scale (Bullard et al 1950, Yukutake 1962, Adam et al 1964). All these recent studies generally agree that the magnetic field of the earth has continued drifting westwards with a mean velocity of about $0.2^{\circ}$ year during the last 50 years or so, though local features of drifting were noted in such regions as Canada and the Pacific Ocean (Whitham 1957, Yukutake 1962, Adam et al 1964, Pochtarev 1964, Vestine 1966, Rikitake 1967).

It was pointed out by Bauer (1896) that there is close relationship between the observed secular variation and the spatial distribution of the geomagnetic field. He plotted changes in the magnetic declination and inclination along a parallel of latitude on a diagram of inclination versus declination, and found that, when the curve specified by declination and inclination was developed eastwards along the parallel, it showed changes very similar to a secular change curve for such historic data as those of London and Paris (Bauer 1896). It was pointed out recently that the main features of long term variation obtained in London, Paris and Tokyo could well be accounted for by the westward drift of the non-dipole field if mean rate of drift was taken as $0.4^{\circ}$ /year (Yukutake 1962). These suggestions support the hypothesis that the non-dipole field has been rotating westerly for a sufficiently long time to contribute appreciably to the observed secular variation.

\section{Westward drift revealed from archeomagnetic data}

A fairly large amount of archeomagnetic data has accumulated during the last few decades. Although the accuracy of archeomagnetic results is considerably less than that of instrumental observation, they still deserve a careful examination for the general features of the geomagnetic secular variation.

Archeomagnetic data as well as old records of magnetic measurements were collected as far as possible. In Figure 2, long term variations in magnetic declination thus collected 

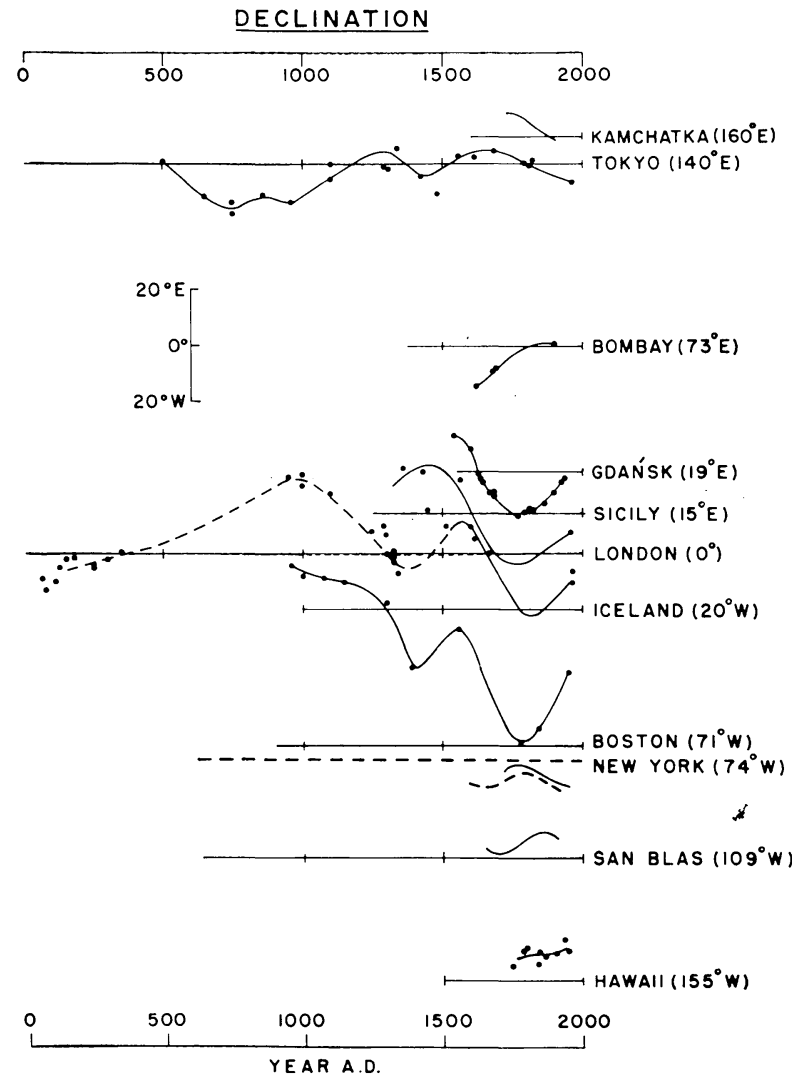

Fig. 2 Time variation in magnetic declination at various places. Most of solid circles are obtained by archeomagnetic investigation. A few points in Tokyo and all of the circles of Bombay and Gdansk are the results of instrumental observation. Variation curves are shown from east to west, so that the distances between the zero lines of declination at different stations may become proportional to the corresponding longitudinal distances of the localities. are shown from east to west approximately in proportion to the longitude of the localities. Solid circles indicate the data obtained by the archeomagnetic method. However, at Bombay and Gdansk, they represent the results of instrumental observation. Variation curves after the 17 th century are mainly based on the repeat observations as at Gdansk. For Sicily, Iceland and Hawaii, curves were extrapolated from archeomagnetic data.

It may be noted on the diagram that one of the maxima in the easterly declination took place in Japan around 1300 A.D., while one was observed in London about 1600 A.D. In North America, a maximum declination appeared around 1800 A.D. It suggests that a peak of declination has drifted westwards.

In Figure 3, the variations in declination in Europe and North America are shown in further detail. The data are taken from US Coast and Geodetic Survey Publication (Bauer 1902), and

rearranged in a way similar to the previous figure, i.e. in a manner proportional to the longitudes. Westward drift of a maximum deviation can be noted more clearly in this diagram.

From these diagrams, dates of maximum and minimum diviation of declination observed at each locality were read off (Table 1) and plotted in Figure 4. It is apparent that the curves in Figures 2 and 3 are very approximate only showing the general features of the variation. The uncertainty included in the dates of maxima and minima listed in Table 1 may possibly amount to as much as \pm 50 years for archeomagnetic data and \pm 20 years for the data of old observations. In spite of these uncertainties, however, Figure 4 suggests clear tendency of westward drift of each maximum and minimum. The slopes of straight lines fitted by the least squares method give mean rate of drift as $0.31 \pm 0.015^{\circ}$ /year for the uppermost 


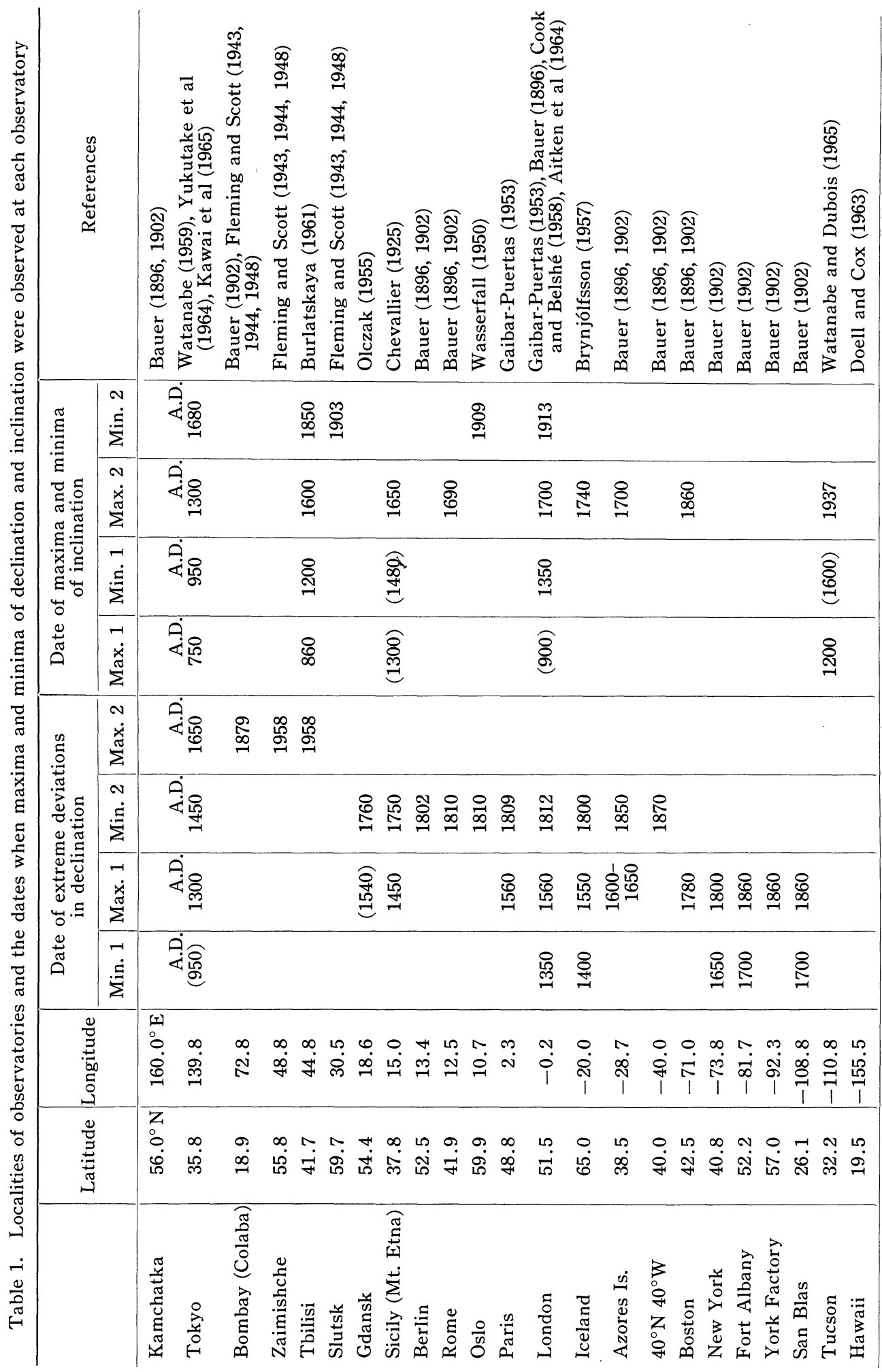




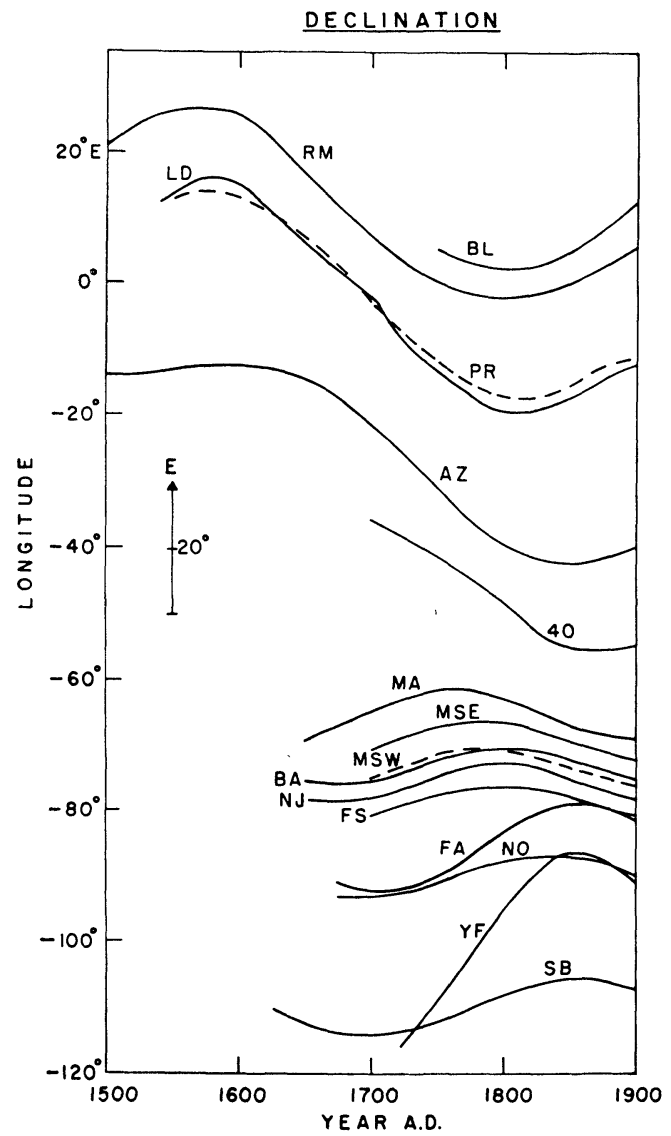

Fig. 3 Secular variation in declination in Europe and North America. Variation curves are shown from east to west in the same way as in Figure 2. Abbreviations used in the figure are listed below.

$\mathrm{BL}:$ Berlin $\left(52.5^{\circ} \mathrm{N} ; 13.4^{\circ} \mathrm{E}\right)$

RM: Rome $\left(41.9^{\circ} \mathrm{N} ; 12.5^{\circ} \mathrm{E}\right)$

PR: Paris $\left(48.8^{\circ} \mathrm{N} ; 2.3^{\circ} \mathrm{E}\right)$

LD: London $\left(51.5^{\circ} \mathrm{N} ; 0.2^{\circ} \mathrm{W}\right)$

$\mathrm{AZ}$ : Azores $\left(38.7^{\circ} \mathrm{N} ; 29.0^{\circ} \mathrm{W}\right)$

$40 ; 40^{\circ} \mathrm{N} 40^{\circ} \mathrm{W}\left(40.0^{\circ} \mathrm{N} ; 40.0^{\circ} \mathrm{W}\right)$

MA: Maine $\left(44.9^{\circ} \mathrm{N} ; 67.0^{\circ} \mathrm{W}\right)$

MSE: Massachusetts East $\left(42.3^{\circ} \mathrm{N}\right.$; $\left.71.0^{\circ} \mathrm{W}\right)$

MSW : Massachusetts West $\left(42.4^{\circ} \mathrm{N}\right.$; $\left.73.3^{\circ} \mathrm{W}\right)$

BA: Baltimore $\left(39.3^{\circ} \mathrm{N} ; 76.6^{\circ} \mathrm{W}\right)$

$\mathrm{NJ}$ : New Jersey $\left(40.2^{\circ} \mathrm{N} ; 74.8^{\circ} \mathrm{W}\right)$

FS: Florida South $\left(28.0^{\circ} \mathrm{N} ; 82.5^{\circ} \mathrm{W}\right)$

FA : Fort Albany $\left(52.2^{\circ} \mathrm{N} ; 81.7^{\circ} \mathrm{W}\right)$

NO: New Orleans $\left(30.0^{\circ} \mathrm{N} ; 90.2^{\circ} \mathrm{W}\right)$

YF : York Factory $\left(57.0^{\circ} \mathrm{N} ; 92.3^{\circ} \mathrm{W}\right)$

$\mathrm{SB}$ : San Blas $\left(26.1^{\circ} \mathrm{N} ; 108.8^{\circ} \mathrm{W}\right)$

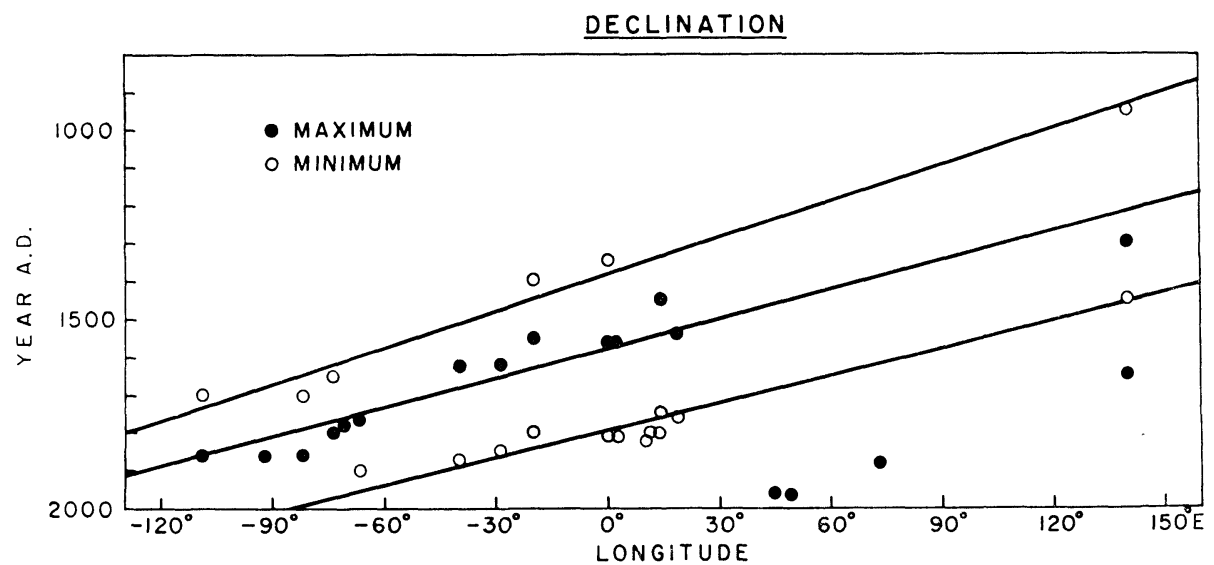

Fig. 4 Dates of maxima and minima of declination observed at each locality. Solid circles show the dates of maxima and open circles those of minima. Linear lines determined by least squares method give westward drift rates of $0.31 \pm 0.015^{\circ} /$ year, $0.35 \pm 0.024^{\circ} /$ year and $0.41 \pm 0.022^{\circ} /$ year from the top to the bottom. 

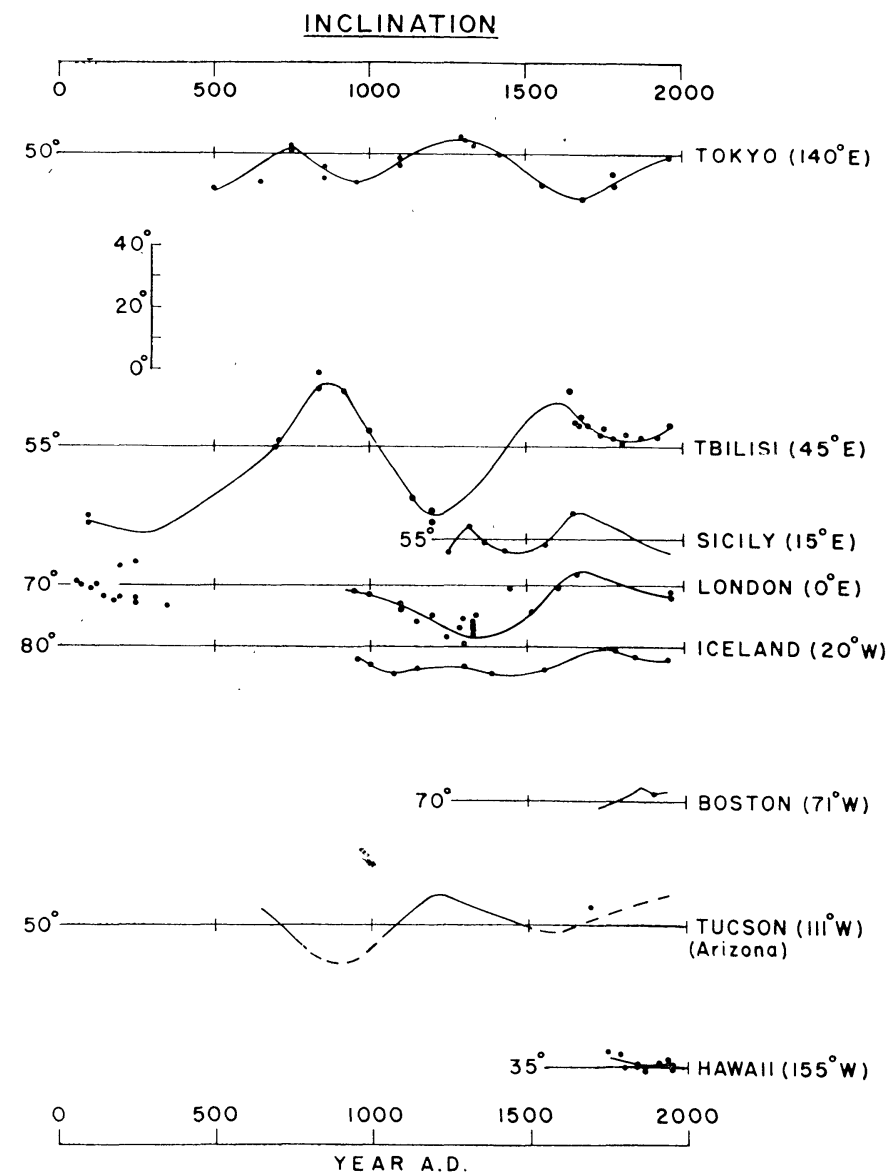

Fig. 5 Time variation in magnetic inclination at various places. Mean values of the inclination are shown on the left of the base lines, which are drawn so as to give relative longitudinal distances from east to west.

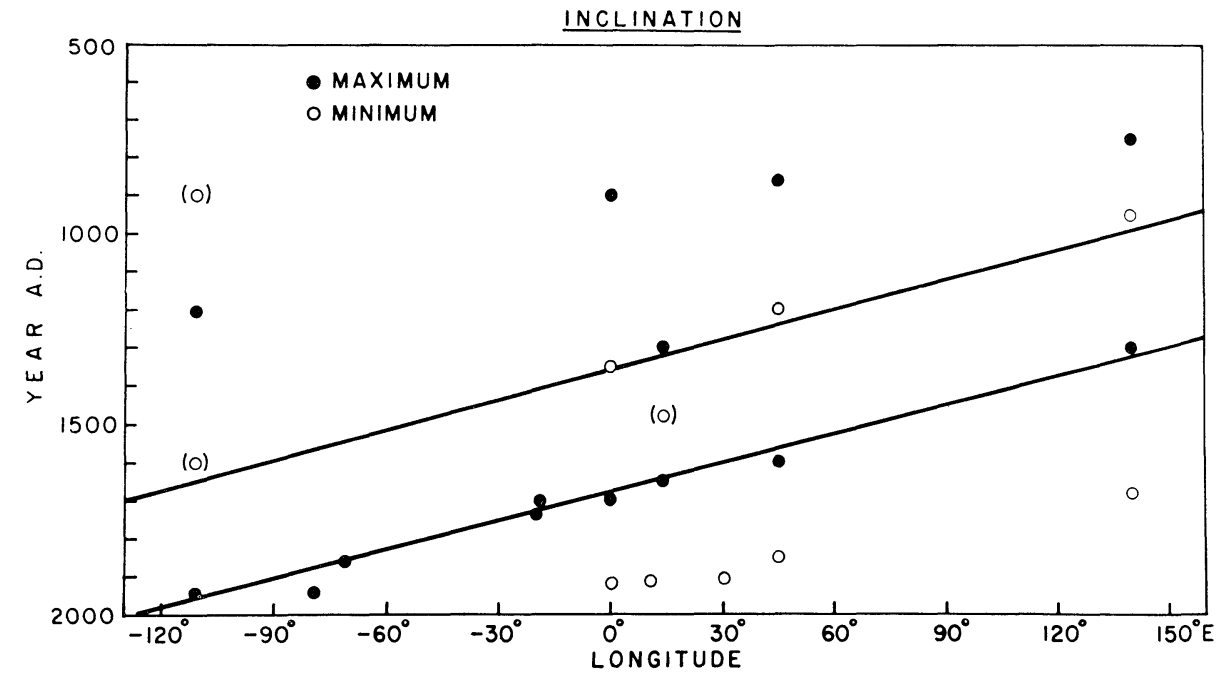

Fig. 6 Dates of maxima and minima of inclination observed at each locality. Solid circles represent the dates of maximum inclination observed at the corresponding longitude, while open circles represent those of minimum inclination. Velocities of westward drift are obtained as $0.33 \pm 0.048^{\circ}$ /year for the upper series of minima and $0.39 \pm 0.13^{\circ}$ year for the lower series of maxima. 
minimum declination, $0.35 \pm 0.024^{\circ} /$ year for the maximum and $0.41 \pm 0.022^{\circ} /$ year for the lowest minimum.

Similarly, we have secular variation curves in magnetic inclination, as is shown in Figure 5. The maxima and minima of the variations were read and plotted in the same way as the previous one, giving mean velocities of $0.33 \pm 0.048^{\circ}$ /year for a series of minimum inclination and $0.39 \pm 0.013^{\circ}$ year for a series of maximum inclination (Fig. 6).

The good agreement between the velocities thus estimated for different series of maxima and minima of declination and inclination seems more than accidental, and hence suggests that magnetic declination and inclination have drifted westwards with a mean rate of about $0.36^{\circ}$ year during the period from 1300 A.D. to 1900 A.D.

\section{Variation in declination in North America}

There are number of stations in North America where magnetic measurements have been conducted repeatedly since the 17 th century. Figure 7 shows the distribution of the repeat stations whose results were used for the present analysis, taken from the Bulletin of the Topographical Survey of Canada (Herbert 1926) and US Coast and Geodetic Survey Publication (Bauer 1902).

Individual measurements were not always repeated regularly nor conducted exactly at the same place. The data used here are not the results of original measurements but the values reduced to those of specific stations at 10 year intervals. Angular errors accompanying the reduction procedure may be less than a degree (Bauer 1902, p. 100, p. 120). This, of course, rules out such small fluctuations which can only be detected by accurate measurements

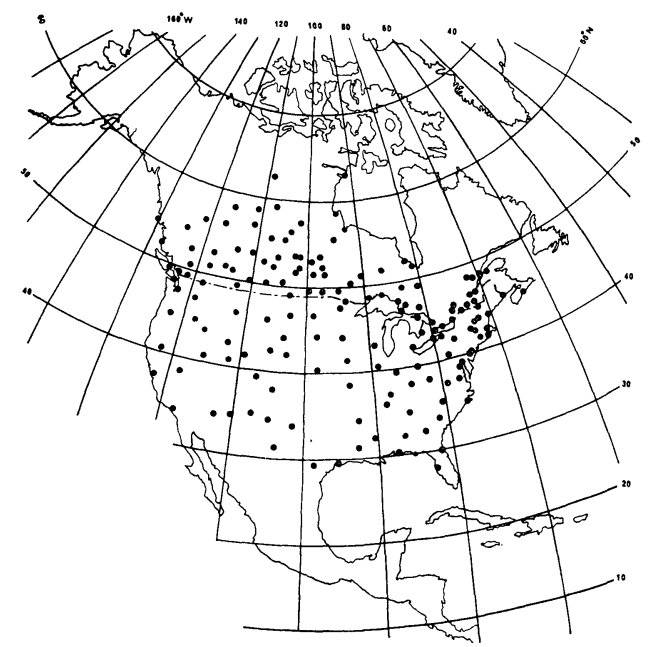

Fig. 7 Distribution of repeat station used for the present analysis.

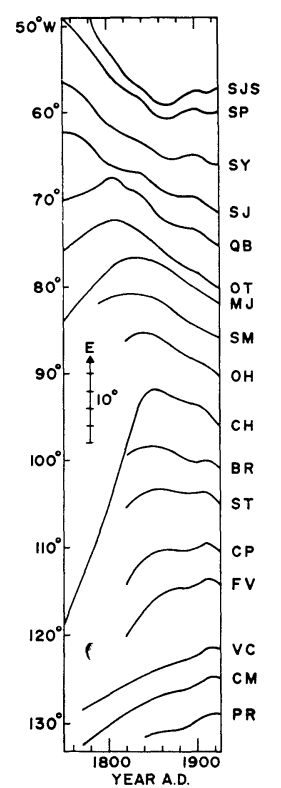

Fig. 8 Examples of time variation in declination obtained by repeat observations in Canada. Variation curves are shown from east to west in a way similar to that of Figs. 2 and 3. 


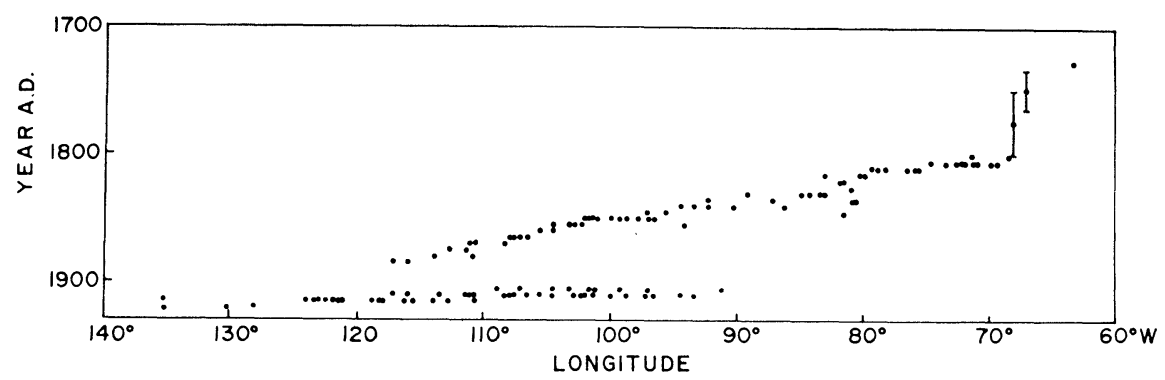

Fig. 9 Dates of maximum easterly declination observed at various longitudes in Canada. The uncertainly involved in determining the date is \pm 5 years. The mean rate of drift for the westerly propagating maxima was obtained as $0.56^{\circ} \pm 0.011^{\circ} /$ year during the period from 1800 to 1925.

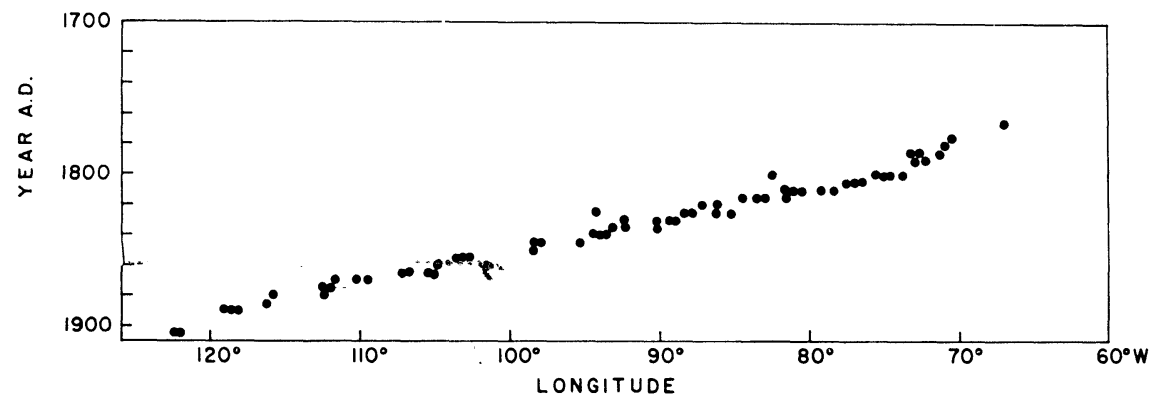

Fig. 10 Dates of maximum easterly declination in USA. The drift rate was obtained as $0.44 \pm 0.008^{\circ} /$ year for the period from 1750 to 1902 .

at permanent observatories. The reduction procedure, however, has the advantage of acting as a sort of low pass filter. The present data can thus be regarded as free from erroneous peaks produced by short period variations superposed on a gradual change.

Figure 8 shows some of the results of the repeat observations for the declination in Canada, covering from 1750 to 1925. A tendency for westward drifting of the extreme easterly declination can be seen. However, it may also be noted that there is another smaller peak which took place nearly simultaneously around 1910.

Dates of maximum declination were read with an accuracy of \pm 5 years, and the relation between the longitudes and the dates when easterly maxima appeared at each station are shown in Figure 9 in a similar way to the previous figures. On the diagram, two different types of maxima may clearly be distinguished. One is progressive, and the other is approximately simultaneous over the area. It has been estimated that the progressive variation propagated westwards with a mean velocity $0.56 \pm 0.011^{\circ} /$ year during the 19 th century, though certein fluctuation are notable, especially during the period from the end of the 18th century to the beginning of the 19th century.

No further investigation of the magnetic variation which took place around 1910 has been made in this paper, other than to note that the event should be discriminated from the variation due to the westward drift of the non-dipole parts of the magnetic field. It is also left uncertain whether the variation took place simultaneously, or if it propagated with too large a velocity to be resolved from the present accuracy of the data. 
Data of the repeat stations in USA (Bauer 1902) were also examined from 1750 to 1910. Figure 10 shows the propagation of the corresponding easterly maxima, giving a velocity of $0.44 \pm 0.008^{\circ} /$ year. The westward drift of the extreme easterly declination in USA was already noticed by Bauer (1902 p. 99). He estimated the drift velocities very roughly as one degree of longitude in two years.

Table 2. Drift velocities of main features of magnetic declination and inclination

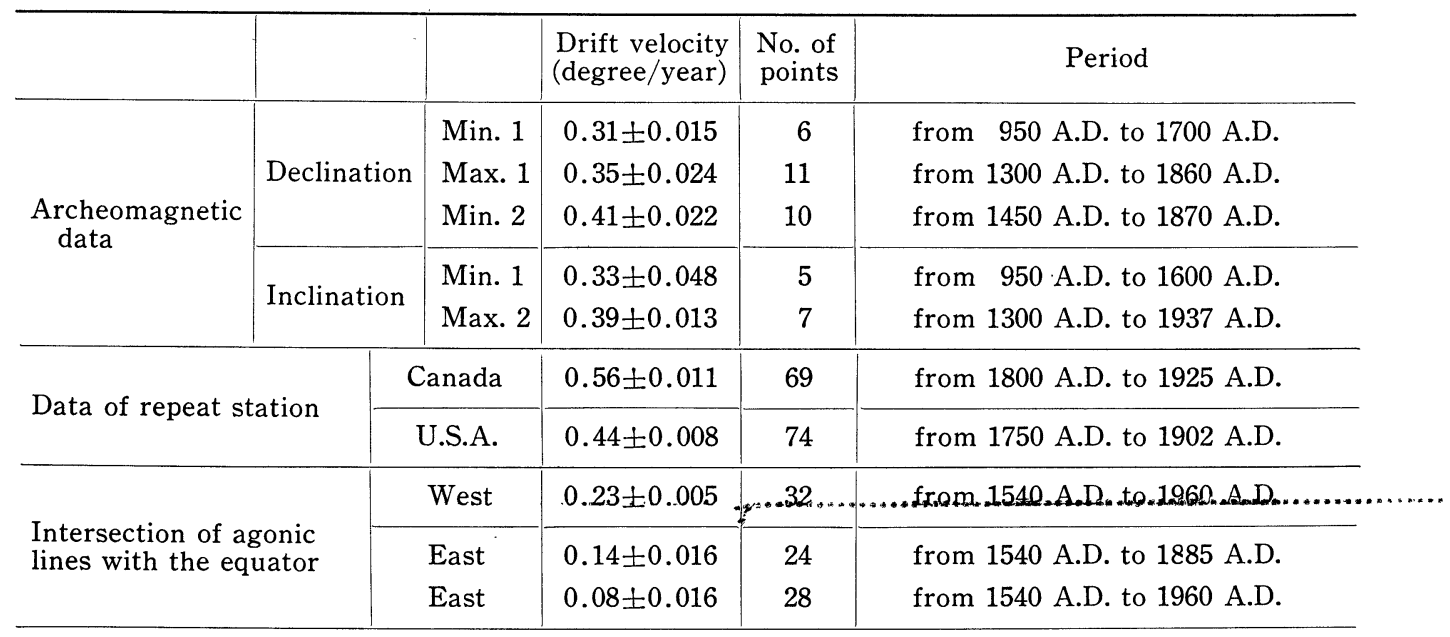

\section{Relationship between the secular variation and the spatial distribution of the field}

In the previous section, the westward drift of magnetic variation has been examined by correlating such marked features as the maxima or the minima of declination and inclination observed at various places. The spatial extent of such magnetic disturbances will be estimated roughly in this section.

A rotating field may be expressed in a form $e^{i m(\varphi-v t)}$, where $m$ is the order of spherical harmonic term, $\varphi$ the longitude and $v$ the drift velocity. Then $m$ can be estimated by $m=\frac{2 \pi}{v T}$, where $T$ is the characteristic period of secular variation observed at a single locality. $T$ was obtained from archeomagnetism as 400 years for declination (Watanabe 1959, Yukutake 1961) and 600 years (Yukutake 1961) or 800 years (Watanabe 1959) for inclination. If $T$ is taken as 600 years and $v$ as $0.36^{\circ}$ year, the mean of the drift velocity for declination and inclination during the last several hundred years, then we obtain $m=1.7$.

This rough estimate suggests that the secular variation observed at a single locality is associated with magnetic disturbances having long wavelengths which can be specified by $m=2$.

Very little is known about the life time of the non-dipole field. If we assume, however, that the present non-dipole field has persisted during the past 1000 years without suffering serious modification, and that it has been rotating around the earth's axis, the drift velocity can be determined so that the time variation expected from the drift may fit best to the observed variation.

Figure 11 shows the secular variation in declination and inclination observed in London. 
Dotted curves are obtained by rotating the present non-dipole field with a velocity of $0.41^{\circ} /$ year, which was determined following the procedure described in the previous paragraph. Similarly, drift velocities for the secular change at other localities were computed (Yukutake 1962), and are reproduced in Table 3.

These velocities are in good agreement with the phase velocities listed in Table 2, which were obtained by tracing the maxima and the minima of decilnation and inclination. It suggests that marked features of the observed secular variation can be caused by drifting of

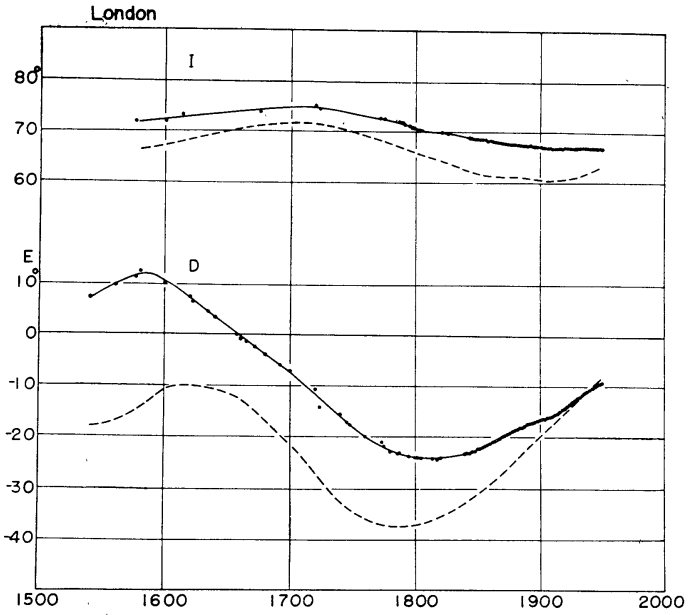

Fig. 11 Secular variation in declination and inclination in London. Solid curves are interpolation for observation (solid circles). Such time variations as shown by dotted curves are expected when the present non-dipole field is rotated westward with a velocity of $0.41^{\circ}$ /year. parts of the earth's field.

From these considerations, the following may be concluded:

a) the westward drift of the magnetic field has been a persisting feature of the secular variation during the last 700 years:

b) the non-dipole parts of the earth's field can exist without serious change over several hundred years:

c) some of the main features of the observed secular variation, even for such a long period as 1000 years, can be accounted for by drifting of the non-dipole field. This result has been well established for data of recent decades.

Table 3. Drift velocities obtained by correlating the historic secular variation with the spatial distribution of the non-dipole field

\begin{tabular}{l|c|c}
\hline & $\begin{array}{c}\text { Declination } \\
\text { (degree/year) }\end{array}$ & $\begin{array}{c}\text { Inclination } \\
\text { (degree/year) }\end{array}$ \\
\hline Oslo & 0.64 & $0.66 \pm 1.20$ \\
London & $0.41 \pm 0.03$ & $0.41 \pm 0.22$ \\
Paris & $0.42 \pm 0.41$ & $0.45 \pm 0.09$ \\
Tokyo & $0.39 \pm 0.01$ & $0.37 \pm 0.02$ \\
\hline
\end{tabular}

\section{Diversity of drift velocities}

Recent investigations conducted for the non-dipole field of the 20th century give the mean rate of drifting $0.2^{\circ}$ year (Bullard et al 1950, Yukutake 1962, Nagata 1962, Adam et al 1964). Compared with this, the drift velocities estimated for historic records in the previous sections appear definitely larger by a factor of approximately two. The discrepancy does not seem 
to arise from errors in the analyses.

No clear explanation has been proposed to reconcile the above discrepancy. Three possibilities are tentatively suggested in this section: (a) the rate of drift has changed at the beginning of the 20th century, (b) dispersive velocity is intrinsic to the westward drift, (c) drift velocity is dependent on latitude.

It might be supposed that the westward drift of the magnetic field has been accompanied by occasional acceleration and deceleration, though the field has continued rotating with the mean rate of approximately $0.4^{\circ}$ year. If old records of repeat observations could be regarded as having the same accuracy as the present ones, such fluctuations in the drift velocity could be recognized in Figure 9 (which shows westerly progress of an extreme easterly declination from the east to the west coast of Canada during 1700 A.D. to 1910 A.D.). For the first half of the 19 th century, a quicker velocity of approximately $0.6^{\circ} /$ year is notable, whilst for the last half a smaller velocity of about $0.2^{\circ} /$ year is indicated. Analysis conducted for east components of the 20th century give drift velocities of $0.17 \pm 0.003^{\circ} /$ year for Kakioka in Japan, $0.18 \pm 0.003^{\circ}$ year for Greenwich, and $0.22 \pm 0.009^{\circ} /$ year for Chambon-la-Forét (Yukutake 1962). These are significantly different from those indicated in the previous sections for the declination of historic data, namely $0.39 \pm 0.01^{\circ} /$ year for Tokyo, $0.41 \pm 0.03^{\circ} /$ year for London and $0.42 \pm 0.41^{\circ}$ year for Paris. A similar situation can be seen in Canada. Examining airborne, ground and repeat magnetic observations, Whitham (1957) concluded that the drift rate in recent years in Canada was significantly smaller than the world-wide average $0.2^{\circ}$ /year. On the other hand, during the 19 th century a specific feature of the secular variation in Canada has been revealed to have drifted with the rather large velocity of $0.56^{\circ} /$ year. These results all support the inference that the drift rate has been subjected to a change at the beginning of the 20th century. However, an objection against this is the movement of the west agonic line along the equator. It seems uniform during the whole period from 1500 to 1960 A.D. (Fig. 1). There is neither an indication of any change in the rate of drift at the beginning of the 20th century nor any such large velocity in the past as $0.4^{\circ} /$ year.

The second possibility to explain the discrepancy of the drift rate is to assume a dispersion of the velocity. From the theory of free oscillation of the earth's magnetic field, Hide (1966) suggested that the drift rate should be strongly dependent on the wavelength of magnetic disturbances or the degree and the order of spherical harmonics. Although no such strong dispersion of velocity as predicted from the theory has actually been observed, it can be demonstrated from the recent analyses that the drift rate becomes larger for the shorter wave lengths. Summarizing the analyses of the westward drift of spherical harmonic coefficients, Hide $\left(1966\right.$, p. 640 ) showed a westerly velocity of $0.05^{\circ} /$ year for the equatorial dipole component $(n=1, m=1), 0.23^{\circ} /$ year for $n=2, m=1$ and $0.38^{\circ} /$ year for $n=2, m=2$. As was estimated previously, the order of harmonics which are concerned with the historic drift is approximately $m=2$, and the mean drift rate is $0.36^{\circ}$ /year for the magnetic declination and inclination. A very good coincidence between the drift velocities for such wave length, seems to suggest that the historic drift is characterized by the drift of the harmonic 
$n=2, m=2$, when expressed in terms of spherical harmonics. On the other hand, for the short period observations it might possibly be supposed that the lower harmonic $n=$ $2, m=1$ is predominant probably because of a sort of filtering process effected by relative importance between the amplitudes of harmonics and the period observed. However the hypothesis of dispersive velocity is not satisfactory to account for the large rate obtained in Canada and Oslo.

The third possibility is to assume a latitude dependency of the drift velocities. In Figure 12, the drift velocities so far obtained for the historic data are plotted against latitude. This seems to suggest that the drift velocity increases with the latitude. The dotted curve in the figure is the angular velocity distribution when the field rotates with a constant linear velocity $0.058 \mathrm{~cm} / \mathrm{sec}$ at the surface of the core irrespective of latitude. As far as historic data are concerned, the latitude dependency presented here seems to explain the different velocities obtained. However, the analysis for the data of the recent several tens of years can only

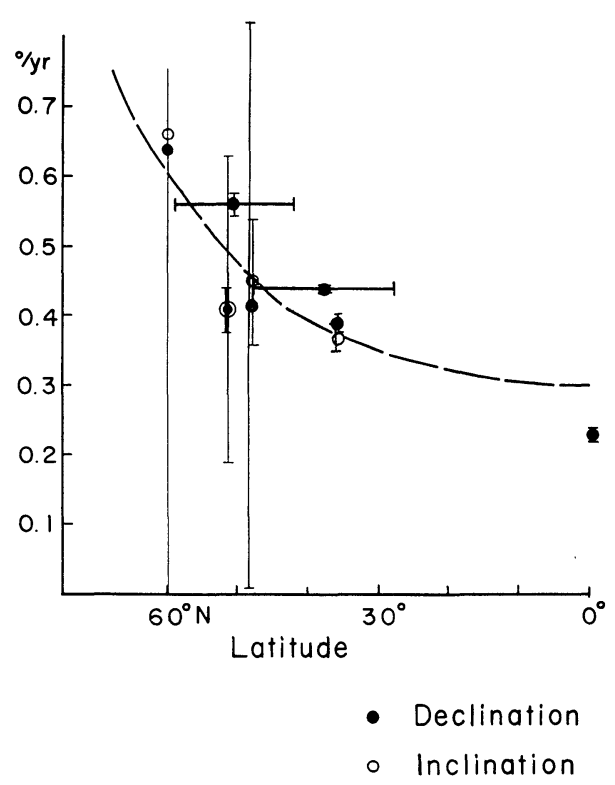

Fig. 12 Distribution of westward drift velocities so far obtained for historic data. Solid circles represent the drift velocities for declination, open circles those for inclination. The data plotted here are, from south to north, for the equator,Tokyo, USA, London, Canada, Paris and Oslo. The broken curve is the distribution of angular velocity when the field rotates with a constant linear velocity of $0.058 \mathrm{~cm} / \mathrm{sec}$ at the surface of the core.

suggest that the drift rate is almost uniform over $60^{\circ} \mathrm{N}$ to $60^{\circ} \mathrm{S}$ (Yukutake 1962). Recent analysis by Kahle and Vestine (1966) suggests a rather larger velocity at the equator. If the present hypothesis is adopted, there is a major discrepancy between the analysis of recent data and historic data at such places as Tokyo, London and Paris.

It seems impossible to account for the diversity of drift velocities by a single hypothesis. It can only be suggested here that the above three hypotheses might each partly be responsible for the variety of the drift rate.

\section{Acknowledgements}

The writer would like to express his sincere gratitude to Dr. K. Whitham for his valuable discussion and remarks given in the course of the study. He also acknowledges Dr. P.H. Serson for his encouragement and interest in this work. Thanks are due to Messrs E. Dawson and L.C. Dalgetty who helped the writer by finding much valuable data in Canada. Drs E. Irving and W. Robertson's suggestions and discussion were very helpful for examining the archeomagnetic data. 


\section{References}

Adam, N.V., Ben'kova, N.P., Orlov, V.P. and Tyurmina, L.O. Western drift of the geomagnetic field, Geomag. Aeron., 4, 434-441 (English) (1964)

Aitken, M.J., Harold, M.R. and Weaver, G.H., Some archaeomagnetic evidence concerning the secular variation in Britain, Nature, 201, 659-660 (1964)

Bauer, L.A., On the distribution and the secular variation of terrestrial magnetism, No. III, Amer. Jour. Sci., 50, 314-325 (1895)

Bauer, L.A., On the secular motion of a free magnetic needle. II, Phys. Rev., 3, 34-48 (1896)

Bauer, L.A., United States magnetic declination tables and isogonic charts for 1902 and principal facts relating to the earth's magnetism, Pub. U.S. Coast Geod. Survey (1902)

Brynjólfsson, A., Studies of remanent magnetism and viscous magnetism in the basalts of Iceland, Adv. Phys., Quart. Suppl. Phil. Mag. 6, 247-254 (1957)

Bullard, E.C., Freedman, C., Gellman, H. and Nixon, J., The westward drift of the earth's magnetic field, Phil. Trans. Roy. Soc. London, A, 243, 67-92 (1950)

Burlatskaya, S.P., Nechaeva, T.B. and Petrova, G.N., The westward drift of the secular variation of magnetic inclination and variations of the earth's magnetic moment according to "Archeomagnetic" data, Izv. Earth Phys. Ser., 6, 280-385 (English) (1965)

Burlatskaya, S.P., Archeomagnetic evidence for the earth's magnetic field near Tiflis during the past, Geomag. Aeron., 1, 707-708 (English) (1961)

Carlheim-Gyllensköld, V., Sur la forme analytique de l'attraction magnétique de la terre, Astron. Iakt. Stockholm, 5, 5, 1-36 (1896)

Chevallier, R., L'aimantation des laves de l'Etna et l'orientation du champ terrestre en Sicile du XII ${ }^{\mathrm{e}}$ au XVII e siècle, Ann. Phys. 4, 5-162 (1925)

Cook, P.M. and Belshé, J.C., Archaeomagnetism : A preliminary report on Britain, Antiquity, 32, 167178 (1958)

Doell, R.R. and Cox, A., The accuracy of the paleomagnetic method as evaluated from historic Hawaiian lava flows, Jour. Geophys. Res., 68, 1997-2009 (1963)

Fleming, J.A. and Scott, W.E., List of geomagnetic observatories and thesaurus of values I, Terr. Mag., 48, 97-108 (1943)

Fleming, J.A. and Scott, W.E., List of geomagnetic observatories and thesaurus of values II, Terr. Mag., 48, 171-182 (1943)

Fleming, J.A. and Scott, W.E., List of geomagnetic observatories and thesaurus of values III, Terr. Mag., $48,237-242(1943)$

Fleming, J.A. and Scott, W.E., List of geomagnetic observatories and thesaurus of values IV, Terr. Mag., 49, 47-52 (1944)

Fleming, J.A. and Scott, W.E., List of geomagnetic observatories and thesaurus of values V, Terr. Mag., 49, 109-118 (1944)

Fleming, J.A. and Scott, W.E., List of geomagnetic observatories and thesaurus of values VI, Terr. Mag., 49, 199-205 (1944)

Fleming, J.A. and Scott, W.E., List of geomagnetic observatories and thesaurus of values VII, Terr. Mag., 49, 267-269 (1944)

Fleming, J.A. and Scott, W.E., List of geomagnetic observatories and thesaurus of values VIII, Terr. Mag., 53, 199-240 (1948)

Gaibar-Puertas, C., Variacion secular del campo geomagnetico, Memor. Obs. Ebro, No. 11, 1-477 (1953)

Halley, E., An account of the cause of the change of the variation of the magnetical needle; with an hypothesis of the structure of the internal part of the earth, Phil. Trans. Roy. Soc., 17, 563-578 (1692)

Herbert, W.H., The march of the compass in Canada, Topogr. Survey Bull. Canada, 58, 3-18 (1926) 
Hide, R., Free hydromagnetic oscillations of the earth's core and the theory of the geomagnetic secular variation, Phil. Trans. Roy. Soc. London, A, 259, 615-650 (1966)

Kahle, A.B., Vestine, E.H. and Ball, R.H., Estimated surface motions of the earth's core, Memorandum RM-5091-NASA, (1966)

Kawai, N., Hirooka, K., Sasajima, S., Yasukawa, K., Ito, H. and Kume, S., Archaeomagnetic studies in Southwestern Japan, Ann. Géophys., 21, 574-578 (1965)

Nagata, T., The main aspects of geomagnetic secular variation-westward drift and non-drifting component, Proc. Benedum Earth Mag. Symp., 39-55 (1962)

Nagata, T. and Syono, Y., Geomagnetic secular variation during the period from 1955 to 1960, Jour. Geomag. Geoelect., 12, 84-98 (1961)

Olczak, T., Secular variation of the magnetic declination at Gdansk, Acta Geophys. Polonica, 3, 27-33 (1955)

Pochtarev, V.I., The western drift of the geomagnetic field, Geomag. Aeron., 4, 289-291 (English) (1964)

Rikitake, T., Non-dipole field and fluid motion in the earth's core, (to be published)

Vestine, E.H., On variations of the geomagnetic field, fluid motions, and the rate of the earth's rotation, Jour Geophys. Res., 58, 127-145 (1953)

Vestine, E.H., Laporte, L., Lange, I. and Scott, W.E., The geomagnetic field, its description and analysis, Carnegie Inst. Wash. Publ., 580, 1-390 (1947)

Wasserfall, K.F., A study on the secular variation of magnetic elements based on data for D, I and H for Oslo, 1820-1948, Jour. Geophys. Res., 55, 275-299 (1950)

Watanabe, N., The direction of remanent magnetism of baked earth and its application to chronology for anthropology and archaeology in Japan: An introduction to geomagnetochronology, Jour. Fac. Sci.Univ. Tokyo, Sec. 5, 2, 1-188 (1959)

Watanabe, N. and Dubois, R.L., Some results of an archaeomagnetic study on the secular variation in the southwest of North America, Jour. Geomag. Geoelect., 17, 395-397 (1965)

Whitham, K., The relationships between the secular change and the non-dipole fields, Canad. Jour. Phys., 3, 3-27 (1958)

Yukutake, T., Archaeomagnetic study on volcanic rocks in Oshima Island, Japan, Bull. Earthq. Res. Inst., 39, 467-476 (1961)

Yukutake, T., The westward drift of the magnetic field of the earth, Bull. Earthq. Res. Inst., 40, 1-65 (1962)

Yukutake, T., Nakamura, K. and Horai, K., Magnetization of ashfall tuffs of Oshima Volcano, Izu, II : Application to archaeomagnetism and volcanology, Jour. Geomag. Geoelect., 16, 183-193 (1964) 